\title{
Freedom and the Way Forward: Liberating Psychoanalysis
}

\section{Bhaskar Sripada*}

\section{Broad Certified Adult and Child Analyst, Chicago Institute for Psychoanalysis, Chicago, USA}

*Corresponding author: Bhaskar Sripada, M.D, Faculty, Broad Certified Adult and Child Analyst, Chicago Institute for Psychoanalysis, Private Practice, Chicago, USA, E-mail: bsripada@gmail.com

Freud practiced both an ideal rule-bound, and a freer principle-based, version of psychoanalysis. If analysts had to choose between the two, Freud's legacy would be one of conflict. If analysts accept both versions, however, his legacy is freedom.

For some time, psychoanalysis has been an object of worship, like a caged bird. Its freedom has been limited by actions analysts have imposed upon themselves, even though each analyst has an independent key to set it, and himself, free. Freud's heirs are struggling with what he bequeathed them. After a long period of strife in the analytic world, there is now a sense of common purpose and a yearning for liberty.

Freud formulated two partially overlapping, partially conflicting versions of psychoanalysis, which I have called Essential Psychoanalysis and Extensive Psychoanalysis [1]. Essential Psychoanalysis is based on the phenomena of the unconscious, transference, and resistance. Extensive Psychoanalysis takes these principles and adds to them adherence to rules of technique, most notably a minimum number of sessions per week and the use of the couch. Freud did not use the terms Essential and Extensive, but practiced them both, thereby setting up the paradoxical situation psychoanalysts struggle with today.

No one is born an analyst. As we strive to grow the next generation of analysts, we must employ the best educational methods possible. To that end, two central elements of psychoanalytic training have been the candidate's own analysis as a patient and his or her supervised analyses of other patients. Almost all analysts intuitively feel that Extensive Psychoanalysis offers the optimal conditions for such training analyses: The frequency and intensity create opportunities for working through significant unconscious transference-resistances within the patient-analyst relationship, and for promoting the patient's growth and insight. Therefore, applying the rules of frequency and the couch are appropriate-indeed, indispensable-in the training of psychoanalyst candidates. Reflecting Freud's personal preferences and the collective wisdom of generations of psychoanalysts, these rules should continue to be considered integral to psychoanalytic training.

Unfortunately, for some time, many analysts have been imposing on themselves mandatory session-frequency and couch rules even in clinical analyses, where there is no educational mission. These stringencies are unnecessary and even counterproductive, resulting in self-inflicted injuries that have diminished psychoanalysis. By not sufficiently differentiating between the educational and clinical missions of psychoanalysis, analysts have unwittingly limited their freedom. Remediation requires the restoration of that freedom.

Except where training functions are involved, Essential Psychoanalysis is the preferred operational definition of psychoanalysis. Psychoanalysis is and should be framed by Freud's [2] statement: "It may thus be said that the theory of psychoanalysis is an attempt to account for two striking and unexpected facts of observation which emerge whenever an attempt is made to trace the symptoms of a neurotic back to their sources in his past life: The facts of transference and of resistance. Any line of investigation which recognizes these two facts and takes them as the starting point of its work may call itself psychoanalysis, even though it arrives at results other than my own". (p. 16) Separately, Freud [3] wrote that psychoanalysis was the science of unconscious mental processes.

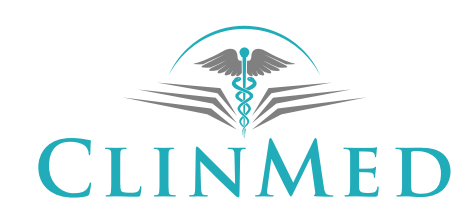

INTERNATIONAL LIBRARY

Citation: Sripada B (2018) Freedom and the Way Forward: Liberating Psychoanalysis. Int J Psychol Psychoanal 4:024. doi.org/10.23937/2572-4037.1510024

Received: June 12, 2016: Accepted: April 23, 2018: Published: April 25, 2018

Copyright: (C) 2018 Sripada B. This is an open-access article distributed under the terms of the Creative Commons Attribution License, which permits unrestricted use, distribution, and reproduction in any medium, provided the original author and source are credited. 
Although analysts have historically acknowledged these ideas, this flexible view of psychoanalysis has fallen into disuse, especially by the American Psychoanalytic Association. My definition of Essential Psychoanalysis echoes Freud: "Any line of treatment, theory, or science which recognizes the facts of unconscious, transference, or resistance, and takes them as the starting point of its work, regardless of its results, is psychoanalysis" [1].

Restating Freud's ideas in a succinct form, Essential Psychoanalysis clarifies the necessary and sufficient conditions for psychoanalysis. It strengthens such claims by asserting that psychoanalysis is composed of unconscious-transference-resistance efforts, regardless of the results, rather than merely allowing that analysts may call such efforts psychoanalysis.

In adding "even though it arrives at results other than my own", Freud anchored the definition of psychoanalysis in his own personhood. Essential Psychoanalysis is not tied to Freud as a person, but to Freud's thoughts and the development of depth-psychoanalytic ideas subsequently derived from those thoughts. Just as Dalton's atomic theory and Newton's theory of gravity no longer encompass the entirety of current atomic or gravitational theories, the definition of Essential Psychoanalysis moves psychoanalysis based on Freud, as a person, to psychoanalysis as a treatment, theory, and science. In neither Freud's nor my definition is there mention of frequency of sessions or the couch. This is because technical considerations are secondary to essential principles.

Freud distinguished his foundational principles unconscious-transference-resistance from rules/recommendations concerning technique (e.g., frequency of sessions, use of the couch, etc.). In describing his own practice, Freud [4] said that he saw patients every day, except Sundays and public holidays, that is, "as a rule, six days a week" (p. 127). He clarified that he had a personal motive in having the patient lie on a sofa while he sat behind him, out of his sight: He did not like being stared at for so many hours a day. He emphasized that his recommendations suited his personality, and he made allowances for other analysts, differently constituted, to use other techniques. He recognized that psychoanalytic technique needed to be modified based on the patient's pathology, the constitution of the analyst, and the specific analytic task. He recognized the extraordinary diversity of the psychical constellations, the plasticity of all mental processes, and other factors that resist any mechanization of technique. An analyst who clearly understands that depth-psychological work is the essence of psychoanalysis will treat frequency and couch criteria as valuable, but secondary. They are manifest/external factors that describe the circumstances under which that analysis takes place.

The term evenly-suspended or hovering attention refers to the analyst's optimal attitude: Non-directive and attentive to the patient's associations without a conscious focus, while being open to his or her own latent thoughts, imagery, and memories. When a traditional analyst who subscribes to the values of Extensive Psychoanalysis is seeing a patient less than four times a week and/or not on the couch, his identity as a psychoanalyst may be threatened. The violation of that frequency/couch norm tugs at his identity, and he may feel diminished by the sense that he is practicing mere psychotherapy, not psychoanalysis. This preoccupation with rules tethers the analyst's attention to a manifest focus and can impede his evenly-suspended attention.

Although Freud formulated the conditions outlined in Extensive Psychoanalysis, he felt no such pangs when he saw patients less than six times a week or not on the couch, and readily called such efforts psychoanalysis. Despite the rules/recommendations and his stated personal preferences, Freud (in keeping with his 1914 definition) felt free to consider as psychoanalysis: A brief chance encounter, in the case of Katherina; a single consultation, in the analysis of Little Hans; and even the case of Judge Schreber, a person he never met. These incidents are persuasive reminders of the freedoms he advocated in 1914; in all of them, the question of frequency of sessions or the couch was moot.

Essential Psychoanalysis is a broad communal mission statement (without secondary details) to which analysts of varying ideas can subscribe. Thus, any work of a trained analyst is psychoanalysis, provided it describes unconscious-conscious, transference-countertransference, or resistance-facilitation in any vignette, element of treatment, or entirety of treatment, according to instinctual, Oedipal, structural, relational, self-psychological, inter-subjectival, developmental, hermeneutical, or neuro-psychoanalytical orientations.

As long as the psychoanalyst considers the facts of the unconscious, transference, and resistance, he or she has the right to call this work psychoanalysis, regardless of the results. That said, the frequency of sessions, use of a couch, limit setting, or other parameters constitute critical technical information about the way an analysis was conducted. A psychoanalyst must exercise freedom and judgment, tempered by his or her own personality, to ensure that every session-indeed, every moment of any clinical situation, theoretical idea, or piece of research-is based on the principles of psychoanalysis and the mission of helping to lessen the patient's suffering. Free associations, along with other freedoms-including those of thought, belief, actions, associations, etc. can all be manifestations of an underlying unifying concept of freedom. Indeed, it can be argued that, subject to ethical, legal, and other reasonable constraints, freedom is the message of psychoanalysis.

The freedom an analyst uses in practicing his or her variety of psychoanalysis must be equally granted to other an- 
alysts who call their work psychoanalysis. This is true, even though the findings and results of one analyst may conflict with those of another. There is a reason that all analysts should recognize the freedom of other analysts to call their unconscious-transference-resistance work psychoanalysis: For decades, many analysts have participated in the psychoanalysis-psychotherapy civil war. Some analysts devalued treatments that embraced unconscious-transference-resistance, but where the patient was seen less than four times a week or did not use a couch, labeling them "psychotherapy". Erikson [5] coined the term "pseudospeciation", the splitting of a single species into multiple false species. In its benign version, it confers positive roles and myths for the in-group; but in the malignant version, the out-group could be marked for ostracism, hostility, and even annihilation.

Many analysts whose work demonstrably rested on the workings of unconscious-transference-resistance (but did not conform to frequency/couch traditions), identified with such aggressive devaluation, subjecting their own work to manifest criteria, and denied themselves the freedom to call their work psychoanalysis. Analysts must stand up and be counted and claim their depth-psychological work as psychoanalysis, regardless of frequency of sessions and use or nonuse of the couch. I believe that pseudospeciation, calling another analyst a non-analyst or his work non-psychoanalysis, is where analysts, as a community, should draw the line.

Historically, comparisons have been made between psychoanalysis and psychotherapy. Many have emphasized frequency of sessions and use of the couch as the defining features of psychoanalysis. In addition, many have claimed that analysis uses neutral interpretations, lack of suggestion or active support, and the development of transference neurosis, resulting in more patient insight and a greater chance of deep structural change; whereas psychotherapy uses less interpretation, the presence of suggestion and active support, and the development of transference reactions, resulting in diminished patient insight and a lesser chance of deep structural change. Empirical studies, beyond the scope of this essay, have found considerable overlap between psychoanalysis and psychotherapy in dealing with unconscious factors in treatment. Currently, there is not much justification for making clear distinctions between psychoanalysis and dynamic psychotherapy.

Contrary to Freud's principle definition of psychoanalysis, the group identity of contemporary psychoanalysts has become enmeshed in Freud's personal technical preferences. Rather than looking for the insightful healing of conflicted suffering and promoting genuine growth whenever possible, some analysts seem to look for it only when a patient is seen four or five times a week. Psychoanalysis and psychoanalysts can do so much more. They can take off their frequency-and-couch blinders and appreciate that their unconscious-transference-resistances work provides for their patients a depth psychological experience. This cannot be found anywhere else. A psychoanalyst's training and expertise can provide great value, wherever employed.

Fenichel [6] agreed with Freud that undoing resistances and interpreting transferences was psychoanalysis and added, "This alone is the criterion. Whether a patient lies down or sits, whether or not certain rituals of procedure are used does not matter" (p. 573). Rangell [7] experimented with a broad therapeutic spectrum, including sporadic hours, telephone sessions, clusters of sessions, double sessions, two separate hours on the same day, and concentrated treatments for time-limited periods. Acknowledging that such experiments can be misused, he stated that he felt that such variations could constitute efforts of a "true psychoanalytic sense", because the key psychoanalytic process is "determined not by outer mechanical but [by] inner processes" (p. 669).

Today, the average number of analytic cases seen by analysts according to the traditional methods is ... one. The classical psychoanalytic model of seeing a patient four or five times a week is collapsing. Insisting on that model can only make the analyst a further endangered species. Trained analysts should use the term psychoanalysis when referring to any unconscious, transference, and resistance work, regardless of the frequency of sessions or the use of the couch. They should stop using the term psychoanalytic psychotherapy to describe such efforts.

Although analysts usually buttress their arguments with case reports, I will deviate from this practice and use an abbreviated version of The Nightingale, by Hans Christian Anderson: The Emperor of China heard that the nightingale had a beautiful song, but no one knew where she lived, except a little servant girl. She led the Emperor's courtiers to the plain-looking nightingale in the forest, and they invited her to sing for the Emperor.

The nightingale said that her song sounded the best in the green woods, but she accepted the invitation. When she sang for the Emperor and his court, the Emperor was greatly pleased, and even shed a tear. He decreed that the nightingale would, from then on, live in the court in her own cage; she would be allowed to go out of the cage twice during the day and once at night. Even on these occasions, however, the servants held her by silken strings fastened to her leg; the nightingale found no pleasure in flying thus bound.

One day, the Emperor received a gift of a mechanical bird covered with jewels that sang when it was wound up. Its song was clear, if predictable. It was arranged that the two birds would sing a duet. The mechanical bird sang beautiful waltzes, while the nightingale sang in her own natural way. The Emperor and the court fell in love with the mechanical bird that seemed to have extraordinary musical powers and was far more beautiful than the plain nightingale. The bird was favored at the court and given an exalted position, on the Emperor's left side, close to his heart. Feeling out of place in 
the confines of the court, the nightingale returned to the forest.

After a while, the mechanical bird broke down. Some years later, the Emperor fell seriously ill and appeared close to death. Hearing of the Emperor's illness, the nightingale returned to heal him and bring hope to the kingdom. Soon, sweet music filled the air. As the nightingale sang, the Emperor revived. Even Death, who was lurking nearby, was so moved that he spared the Emperor's life. Psychoanalysis is the bird of freedom. Listen to its song.

\section{References}

1. Sripada B (2015) Essential Psychoanalysis: Toward a Re-Appraisal of the Relationship between Psychoanalysis and Dynamic Psychotherapy. Psychodyn Psychiatry 43: 396-422.

2. Freud S (1914) Remembering, repeating and working-through
(Further Recommendations on the Technique of Psycho-Analysis II). The Standard Edition of the Complete Psychological Works of Sigmund Freud. The Case of Schreber, Papers on Technique and Other Works, 145-156.

3. Freud S (1925) An Autobiographical Study. The Standard Edition of the Complete Psychological Works of Sigmund Freud. An Autobiographical Study, Inhibitions, Symptoms and Anxiety, The Question of Lay Analysis and Other Works, 1-74.

4. Freud S (1913) On beginning the treatment (Further recommendations on the technique of psycho-analysis I). J Strachey, The standard edition of the complete psychological works of Sigmund Freud. Hogarth Press, London, 121-144.

5. Erikson, H Erik (1977) Toys and reasons. W.W. Norton, New York, USA.

6. Fenichel O (1972) The psychoanalytic theory of neurosis. W.W. Norton, New York, USA.

7. Rangell L (1981) Psychoanalysis and dynamic psychotherapy-Similarities and differences twenty-five years later. The Psychoanalytic Quarterly 50: 665-693. 